\title{
A esfuziante - ainda que velada - forma do som
}

\author{
Maria Helena Serôdio
}

Todos os que caem,

de Samuel Beckett,

enc. João Mota,

Comuna - Teatro de

Pesquisa, 2006

(Maria do Céu Guerra

e Carlos Paulo),

fot. Pedro Soares.

Embora com algumas

reticências, Beckett permitiu a realização televisiva da peça em 1963 (dir. Michel Mitrani)

Os aspectos biográficos

que podem esta

presentes nesta peça

foram referidos pelo seu

biógrafo James Knowlson, Damned to Fame. The Life of Samuel Beckett (1972), Londres, Pocket Books,

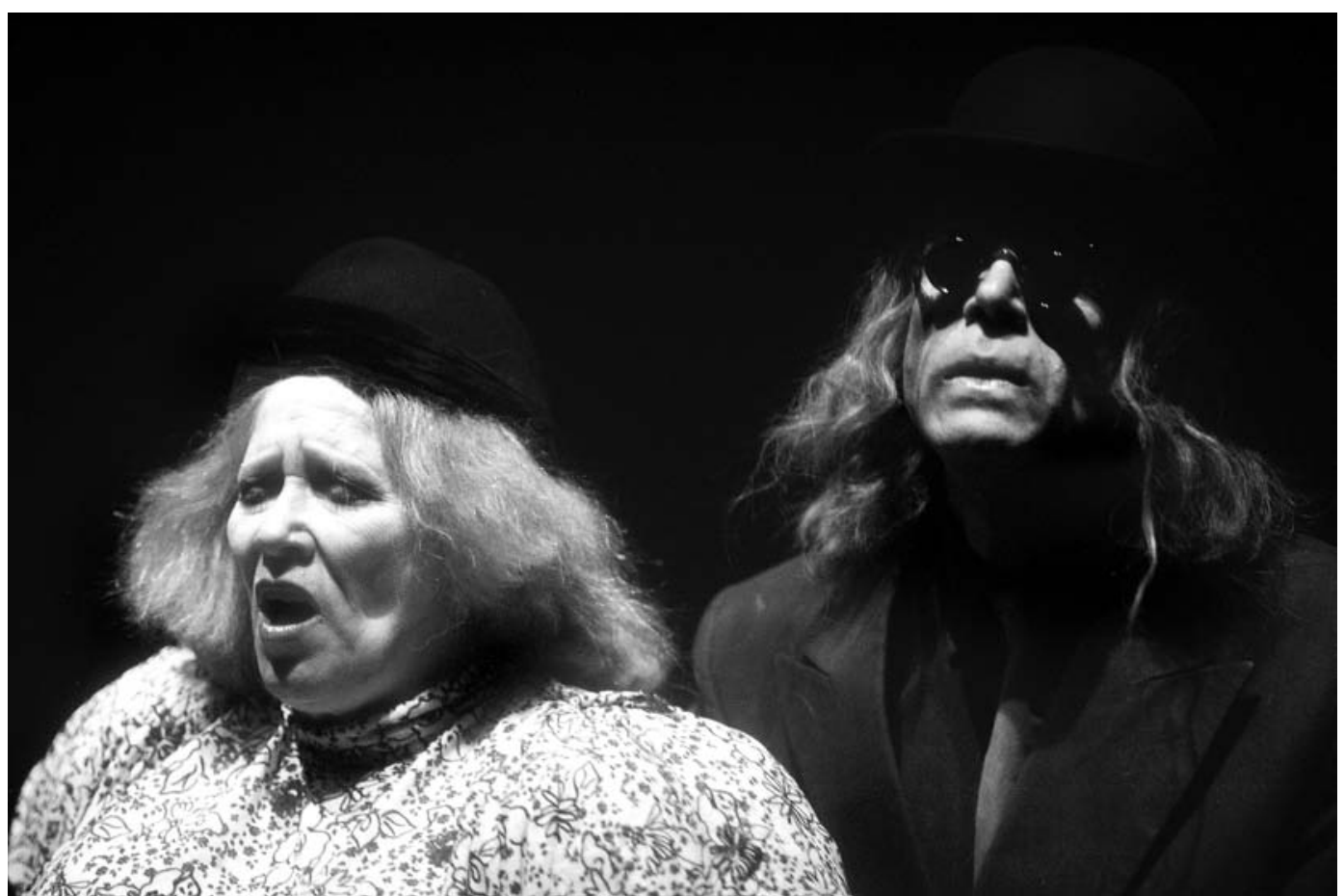

Titulo: Todos os que caem (All that Fall, 1956). Autor: Samuel Beckett. Tradução:Carlos Machado Acabado. Direcção: João Mota. Ambiente sonoro: José Pedro Caiado, Hugo Franco. Desenho de luz: João Mota. Figurinos: Carlos Paulo. Interpretação: Maria do Céu Guerra, Miguel Sermão, Hugo Franco, Álvaro Correia, João Tempera, Victor Soares, Ana Lúcia Palminha, Sara Cipriano, Alexandre Lopes, Carlos Paulo, Luís Filipe Costa. Produção: Comuna Teatro de Pesquisa. Local e data de estreia: Teatro da Comuna (Sala das Novas Tendências), 19 de Janeiro de 2006.

0 gosto de João Mota por processos experimentais, que em 1972 Ihe inspirou (e a alguns outros actores) o gesto fundador da companhia que ainda hoje dirige, fê-lo escolher, em ano de centenário do nascimento de Beckett, iniciar-se na sua dramaturgia com uma peça radiofónica que só agora, com ele, se estreia em Portugal ${ }^{1}$. E, para lá desse desafio, a que respondeu de forma inspirada, não será possivel esquecer que, enquanto "actor", João Mota se estreou com oito anos de idade, justamente na Emissora Nacional. Não terá sido esse, muito provavelmente, 0 fundamento maior para a opção por esta peça, mas não deixa de ser importante que quem encenou este espectáculo tenha feito esse percurso e contactado com essa realidade.

Apesar de a peça ser posterior (em 4 anos) a Ȧ espera de Godot - que, de forma tão ousada, rompia com a convenção da peça realista ou de forte intriga -, há na fabricação de Todos os que caem - que, aliás, responde a uma encomenda da BBC - uma maior acomodação ao formato tradicional (neste caso, da peça radiofónica) e uma mais visivel ancoragem a um naturalismo rural, que não deixa de lembrar as suas raízes irlandesas ${ }^{2}$, bem como a dramaturgia de J. M. Synge ou Lady Gregory (mais do que a do simbolista W.B. Yeats ou a do ambiente realista do proletariado urbano de Sean O'Casey).

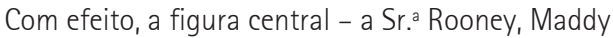
Rooney - é construída de forma elaborada como uma mulher credivel do ambiente provinciano, e que, no seu caminho para a estação de comboio, vai falando com vizinhos e conhecidos. Por seu lado, a topografia sinalizada discursivamente - de uma hipotética Boghill - coincide com a imagem que possamos ter de uma vilória irlandesa. E é ainda verdade que as muitas sonoridades que vão sendo concitadas para a partitura radiofónica são de um verismo que ressuma uma paleta variada e sugestiva de convincente ruralidade, com a ovelha, o galo, a vaca, 0 comboio, etc. 

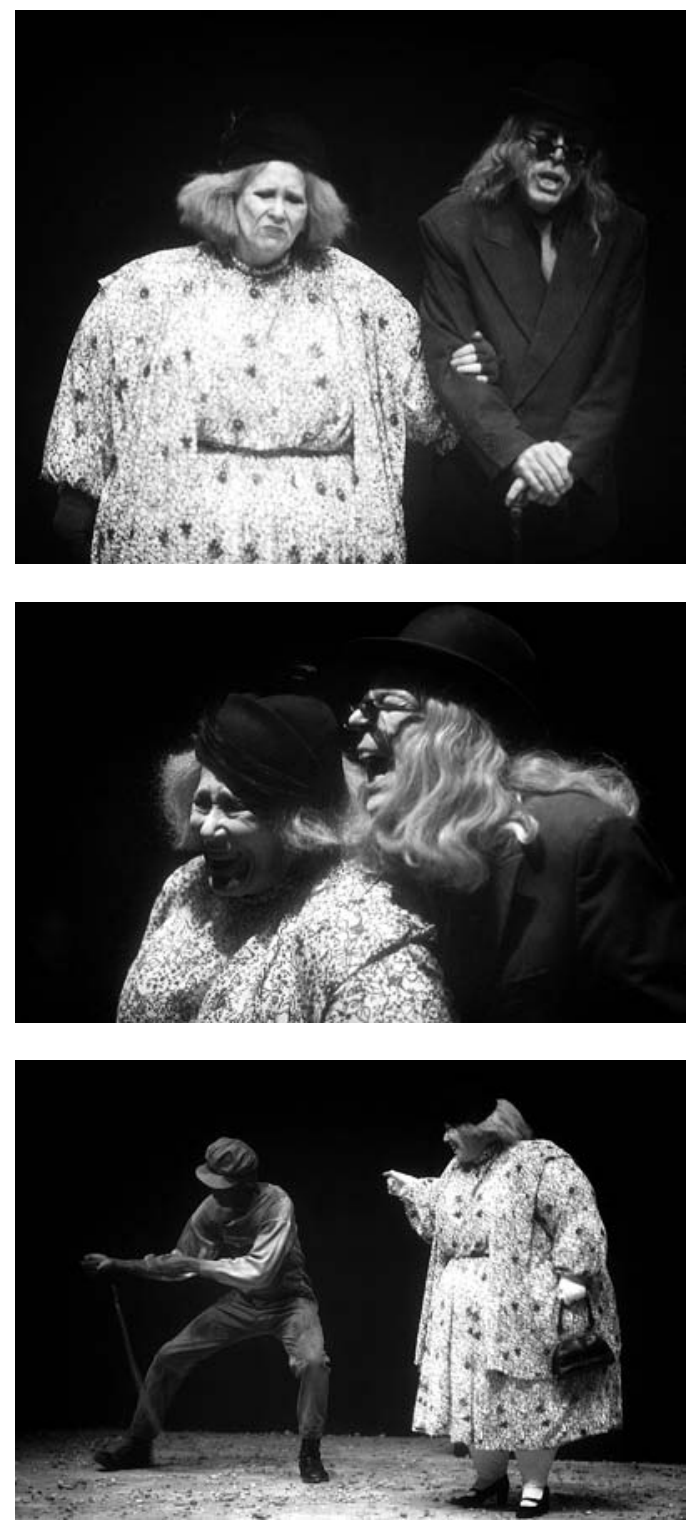

Mas há também traços muito reconhecidamente "beckettianos" que atravessam este universo ficcional: as limitações físicas das personagens (a cegueira do Sr. Rooney e a dificuldade de andar da Sr. ${ }^{a}$ Rooney, gorda e cheia de reumatismo), a ironia cruel de muitos dos seus comentários, um vago enigma sobre a razão do atraso do comboio (terá o Sr. Rooney sido responsável pela queda na linha de uma criança?), o traço paródico na citação bíblica de que foi retirado o título ${ }^{3}$, a suspeita de que talvez toda a "acção" exterior não deixe de ser uma cena puramente imaginada pela mulher numa forma muito própria de sobreposição de vozes. E, nesse sentido, a invisibilidade dos corpos própria da criação para a rádio - serve bem essa ideia de construção mental. De resto, Jonathan Kalb, falando da primeira emissão radiofónica em 1957, refere ter havido um tratamento deliberadamente diferenciado das vozes: Maddy Rooney (por Mary O'Farrell) falava mais perto do microfone e muitas vezes, sobrepunha a sua voz ao início e fim da fala das outras personagens (1996: 127)

Por outro lado, esta fixação nas vozes não deixa de assombrar outros textos dramáticos beckettianos, mesmo os mais minimalistas, quantas vezes confrontando Falante (Leitor ou Contador) e Ouvinte (Não eu (Not I), O improviso de Ohio (Ohio Impromptu), Eh Joe, Passos (Footfalls)), outras reduzindo estas entidades a uma só figura que ouve uma gravação da sua própria voz ou ouve as suas palavras como se elas, enigmaticamente, viessem de algures ( $A$ última gravação de Krapp (Krapp's Last Tape), Aquela vez (That Time), Baloiço (Rockaby)). Didier Anzieu argumenta mesmo que o mito de Eco, sem voz própria e impossibilitada de ter um amor partilhado, é subliminar a muitas das criações deste dramaturgo irlandês (1990: 41).

É nesse formato de vozes encenadas que gostaria de falar deste espectáculo da Comuna, ainda que isso signifique passar ao lado de algumas das muitas virtualidades de sentido da peça que, de resto, Armando Nascimento Rosa analisa de forma sistemática e bem argumentada no texto do programa ${ }^{4}$. É o caso, por exemplo, do possível significado simbólico dos nomes (de figuras e de localidades), ou de uma imaginativa hipótese hermenêutica (de sentido assumidamente gnóstico) que o autor constrói com mal disfarçado - e interessantíssimo - furor inventivo.

A produção da Comuna, baseada numa tradução que me pareceu cuidada, teatralmente funcional e estilisticamente feliz de Carlos Machado Acabado, trazia à cena muitos dos traços que vêm definindo a estética electiva de João Mota, ao mesmo tempo que revivificava em cena um texto que, tendo sido escrito para a rádio, ganhava uma expressividade cénica notabilissima. Não foi, por isso, de admirar que a produção fosse colocada na Sala das Novas Tendências, de formato mais reduzido, com uma exposição frontal e uma relação mais próxima entre a cena e os espectadores.

Entretanto, na criação da imagem cénica estiveram dois elementos estruturantes que, de algum modo, sinalizavam a especificidade de uma peça que não fora escrita para o palco: a disposição dos actores em cena e a cortina translúcida que os separava do público. No primeiro caso, viam-se, encostados à esquerda e à direita do palco, em linha, os actores sentados em frente de mesas de trabalho onde instrumentos simples eram usados para fazer os ruídos pedidos no texto, como se se tratasse de um estúdio radiofónico. No segundo caso - o da cortina translúcida -, tratava-se de um dispositivo que jogava numa dupla sinalização: por um lado, como a parte frontal de certos rádios antigos (aliás, havia um destes aparelhos no lado exterior esquerdo da cena aparecendo esta como, eventualmente, a amplificação do objecto), ou então como um ecrã de filme ou televisão onde, através da geometrização a duas dimensões, se dá a ver uma imagem; e, por outro lado, como a questionação dessa visibilidade,
Todos os que caem, de Samuel Beckett enc. João Mota, Comuna - Teatro de Pesquisa, 2006 (Maria do Céu Guerra e Carlos Paulo), fot. Pedro Soares.

Todos os que caem, de Samuel Beckett enc. João Mota, Comuna - Teatro de Pesquisa, 2006 (Maria do Céu Guerra e Carlos Paulo), fot. Pedro Soares.

Todos os que caem de Samuel Beckett, enc. João Mota, Comuna - Teatro de Pesquisa, 2006 (Miguel Sermão e Maria do Céu Guerra), fot. Pedro Soares.

3 "O Senhor ajuda a levantar todos os que caem e reanima todos os que desfalecem", Salmo 145 (144), versículo 14, in Biblia sagrada: A boa

\section{nova, trad.}

interconfessional do

hebraico, do aramaico e do grego em português corrente, Lisboa, Difusora Biblica, 1993. Na versão "autorizada" da Biblia em inglês, sob o reinado de Jaime l o salmo é: "The Lord upholdeth all that fall, and raiseth up all that be bowed down".

${ }^{4}$ É possivel ler este seu texto em htttp://www.triplov.com /coloquio_05/armando_ rosa.html. 
Todos os que caem,

de Samuel Beckett,

enc. João Mota,

Comuna - Teatro de

Pesquisa, 2006

(Álvaro Correia

e Maria do Céu Guerra),

fot. Pedro Soares.

uma vez que nem o ecrã era de cristalina transparência, nem a imagem cénica pretendia naturalizar a representação. Esta ostensiva "teatralização" decorria de dois procedimentos básicos: por um lado, os actores que estavam sentados a produzir os sons "entravam em cena" de vez em quando para contracenar com as figuras principais (a Sr. ${ }^{a}$ e o Sr. Rooney, interpretados por Maria do Céu Guerra e Carlos Paulo, respectivamente), e, por outro lado, verificava-se

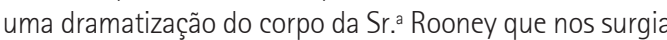
inchada como uma figura do pintor colombiano Fernando Botero e a que Céu Guerra conferia uma força redobrada pela expressão do riso entre o derrisório e o demencial.

Dois outros elementos abriam o espectáculo da Comuna explicitamente reconduzindo-o a uma realidade radiofónica: a voz em off de Luís Filipe Costa, realizador de cinema, mas a cuja voz aos microfones da rádio nos habituámos durante muitos anos e que, na madrugada do 25 de Abril, teve o importante papel de anunciar uma das canções que funcionaria como o detonador do movimento dos capitães: Edepois do adeus, de Paulo de Carvalho. A sua voz, sobre um breve trecho musical, dizia na abertura do espectáculo "Noite de teatro", ao mesmo tempo que uma luz incidia sobre o velho aparelho de rádio colocado fora da cena, à esquerda. Entravam depois sons de vozes de animais que os espectadores localizavam já em cena por vermos a sua "produção" a partir dos instrumentos usados em estúdio

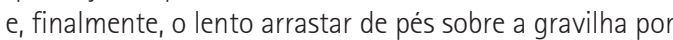
parte da actriz, enquanto se ouviam os acordes de A morte e a donzela ${ }^{5}$, de Schubert. Esta referência musical acabava por funcionar como uma espécie de lead em termos musicais, introduzindo o tema da morte de uma figura feminina - jovem (de que se falará na peça em diversas identificações), ao mesmo tempo que criava um ambiente sonoro e reconduzia à realidade radiofónica da peça.

Na configuração plástica da cena, eram de destacar em todas as figuras os chapéus, icones bem beckettianos, ao mesmo tempo que vagos traços de figurinos dos anos 50 jogavam não só com a data da peça, mas, mais que tudo, com um tempo em que a rádio era ainda o meio de comunicação mais difundido e presente em todo o lado. No espaço limitado da cena muitas eram as "presenças" referidas - a mula, a bicicleta, o carro, o comboio, etc. que se imaginavam a partir dos movimentos ou dos gestos dos actores, na habitual depuração que João Mota traz à cena, sempre destacando a figura humana e privilegiando

${ }^{5}$ Em termos de memória teatral entre nós, recorde-

se que a peça do argentino Ariel Dorfman com este mesmo titulo, publicada em 1991, e que inspirara a Polanski um filme em 1994, foi levad à cena no Teatro Aberto o gosto da fantasia com que o espectador se relaciona com a cena. Resultavam excelentes os trabalhos de expressiva fisicalidade de vários actores, sem que isso os levasse à paródia simples, mantendo, pelo contrário, a tensão entre o esforço e a sua repetida "desvalorização", e reconduzindo, com gosto, a cena à ideia de um jogo teatral subtil, entre a compaixão e a troça. E naquele pequeno quadrado de cena, que ao fundo se elevava com um lanço de escadas que conduzia à estação de comboio, não era possivel definir grandes percursos para as

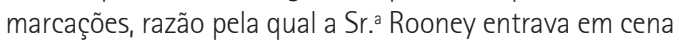

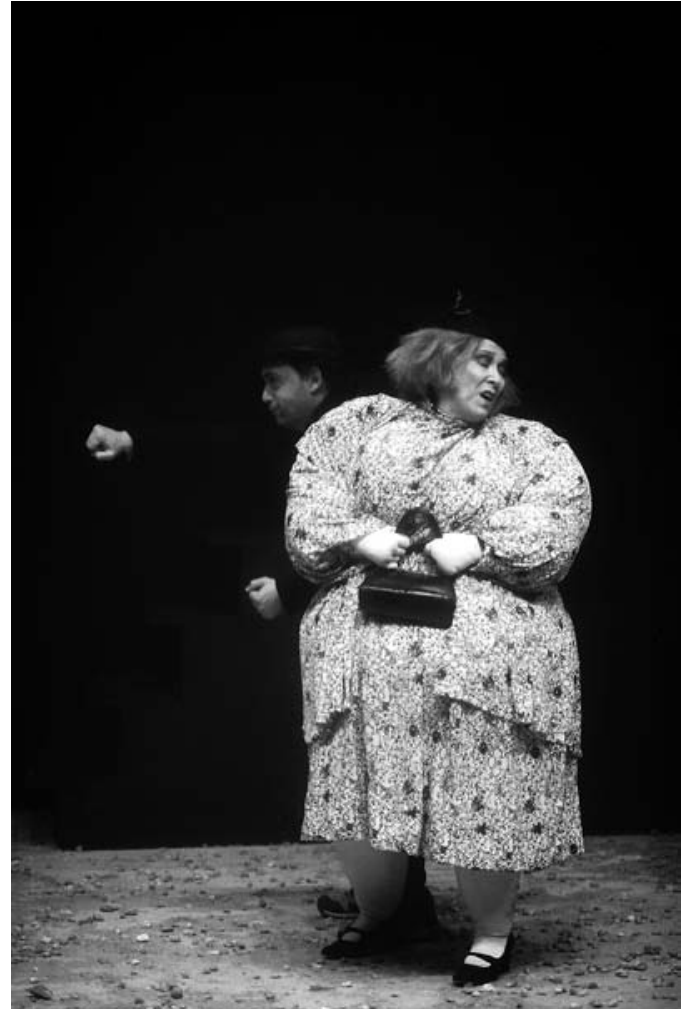

pela direita alta caminhando depois na direcção do público e revolvendo os seus passos numa constante atribulação para a frente e para os lados, dando conta desse fingimento que a peça e o espectáculo gostosamente revelavam.

No conjunto das interpretações destacava-se naturalmente a actriz Maria do Céu Guerra num trabalho de admirável composição, não só na construção exterior da figura, mas também no arrebatamento interior (e sua paródia, simultaneamente), marcando um momento de grande fulgor na sua carreira, e tornando claro que o diálogo entre artistas de diferentes companhias e percursos pode resultar num desafio artístico de importantes consequências. Carlos Paulo, como o Sr. Rooney, num recorte de grande expressividade, Miguel Sermão como Christy, num jogo de eloquente gestualidade, e, em geral, todo o elenco trazia à cena uma brilhante recriação do universo dramático de Beckett. Que, como escreveu Bernard Dort, " [se] organiza como um cruzamento de escritas cénicas virtuais" (1990: 232), e que neste caso, de encenação de vozes, João Mota soube tão bem - com a sua sensibilidade e fina inteligência - esconjurar num dos palcos da sua Comuna.

\section{Referências bibliográficas}

ANZIEU, Didier (1990), "Le théâtre d'Echo dans les récits de Beckett ", in Revue d'Esthétique, Hors série, Paris, pp 39-43.

BISHOP, Tom (1990), "Transpositions pour la télévision: transmutations des œuvres de Beckett ", in Revue d'Esthétique, Hors série, Paris, pp. 385-388.

DORT, Bernard (1990), "L'acteur de Beckett: avantage de jeu" in Revue d'Esthétique, Hors série, Paris, pp. 227-234

KALB, Jonathan (1996) "The mediated Quixote: the radio and television plays, and Film", in The Cambridge Companion to Beckett, Cambridge, CUP, pp. 124-144. 